\title{
IMMUNE HABITUAL ABORTION: INCIDENCE AND MANAGEMENT
}

\author{
Mohamed El Samra, Mohamed El Abd, \& Sherif Agag \\ Department of Obstetrics \& Gynecology, \\ Alexandria University, Egypt
}

\section{ABSTRACT}

The objective of this study of patients with habitual abortion, was planned to determine their autoimmune profile and to try to prevent new abortions using low-dose aspirin (Rivo ${ }^{(1)} 75 \mathrm{mg}$ ) for 7 months with solupred ${ }^{(1)} 20 \mathrm{mg}$ in the first trimester only, or with low-dose aspirin alone. A total of 100 patients with three or more HA were investigated for antiphospholipid antibodies, antinuclear and anti thyroid antibodies. Among these paticnts, auto antibodies were present in $34 \%$ of the patients, in $82.4 \%$ of them anticardiolipin antibodies were found to be isolated alone or associated with lupus anticoagulant, anti thyroid, or, antinuclear antibodies. In auto antibodies-negative pregnant women treated by solupred and aspirin or aspirin alone, the success rate of live births was $90.9 \%$ (30 out of 33) and $75.7 \%$ (25 out of 33) respectivley $(\mathrm{p}<0.01)$ in auto antibodies - positive patients treated with solupred and aspirin the success rate was $85.2 \%$ (29 out of 34) (not significant) solupred and aspirin seemed to be as efficient in auto antibodies - negative or positive women but better than aspirin alone in autoantibody - negative women.

\section{INTRODUCTION}

Habitual abortion is defined as 3 or more consecutive spontaneous abortions, which is a frustrating problem for both the patient and the clinician. It affects about $1 \%$ of those women who are desiring pregnancy ${ }^{(1)}$.

the causes of habitual abortion are diverse which may be due to anatomical, hormonal, genetic abnormalities, infections or autoimmune mechanisms. ${ }^{(2,3)}$ Immunologic causes for spontaneous abortion or failure of implantation are thought to be the result of abnormalities in antibody responses (4). A fetus develops from genetic material from both mother and father. An abnormal immune response may therefore occur against the mother's genetic contribution (autoimmune) or the father's (alloimmune) ${ }^{(5)}$.
Eighty percent of the unexplained pregnancy failures are proposed to have an immunological background. The frequency of autoantibody association with habitual abortion differs greatly from one study to the other, depending upon the way patients are recruited, tests performed and their threshold values ${ }^{(4,5)}$.

Although many studies have focussed on the understanding of habitual abortion, about one third of them remains unexplained ${ }^{(6)}$.

There is no doubt that lupus anticoagulant is a major cause for recurrent pregnancy loss even in women who did not present with systemic lupus erythematosus ${ }^{(7)}$. On this basis, it was decided that glucocorticoids and aspirin treatment should be used to try to prevent abortion ${ }^{(8,9)}$.

Not only lupus Anticoagulant can cause habitual abortion but also recent studies have

Corresponding author : Mohamed El Samra, Department of obstetrics and Gynecology, Alexandria University

E-mail: Dr_clsamra@yahoo.com. 
shown the presence of multiple autoantibodies in the body of habitual aborters ${ }^{(10-12)}$.

The objective of this study was to determine the autoimmune profile of Apparently healthy women with habitual abortion by searching for Anticardiolpin antibodies, lupus anticoagulant (LA) antinuclear antibodies (ANA) and Antithyroid antibodies (a Th) to assess the possible prevention of a new abortion, in autoantibody positive or - negative (Rivo ${ }^{(} 75 \mathrm{mg}$ ) until the end of the seventh month with or without glucocorticoids (Solupred ${ }^{\circledR} 20 \mathrm{mg}$ ) in the first trimester of pregnancy.

\section{MATERIALS \& METHODS}

Hundred healthy patients with habitual abortion were included in this study aged between 20 to 30 years. All these cases were subjected to:

(1) Full history taking.

(2) Routine laboratory investigations which include:-

- Complete blood count.

- Fasting blood sugar

- Renal function tests

- Liver function tests

- Coagulation profile

- Complete urine analysis

(3) Radiological \& Imaging evaluation including

- Hysterosalpingography.

- Ultrasonography

(4) Special tests:*

- IgG and IgM anticardiolipin antibodies measured by ELISA.

- Lupus anticoagulant (LA) measured by coagulation assay.

- Antinuclear antibodies (ANA) measured by ELISA.

- Antithyroid antibodies (a Th).

- Thyroglobulin antibodies (TG-Ab)

- Thyroperoxidase antibodies (TPO-Ab) measured by ELISA.

\section{RESULTS}

Auto antibodies were found to be positive in 34 patients out of 100 patients with habitual abortion while $66 \%$ of the patients were antibodies negative (Table I).

the most frequent Auto antibodies were aCL which were found in $82.4 \%$ of cases ( 28 out of 34 ). IgG aCL were present in almost three out of four cases and IgM aCL in about $35 \%$.

LA were observed in only $1 \%$ out of all the patients and mostly associated with aCL. $79.4 \%$ of the auto antibodies were found alone and $20.6 \%$ were found to be associated with one or two other auto antibodies (Table II).

In auto antibodies-negative women, the rate of live birth in the group of women treated with solupred $\left.{ }^{(}\right)$in the first trimester and aspirin until the end of the seventh month was significantly increased compared with women treated with aspirin alone: $90.9 \%$ of women (30 out of 33) treated with prednisone and aspirin had live births compared with $75.7 \%$ of women (25 out of 33 ) treated with aspirin alone $(\mathrm{P}<0.01)$. In auto antibodies positive women treated with solupred $\left.{ }^{(}\right)$ and low dose aspirin the success rate was $85.2 \%$ ( 29 out of 34 ) the rate of live births was $85.2 \%$; there was no significant difference in the rate of live births between auto antibodies - negative and auto antibodies - positive women $(\mathrm{P}>0.5)$. (Table III).

\section{DISCUSSION}

The percentage of auto antibodies in our study of habitual abortion (HA) patients was $34 \%$, in which aCL were present in the majority of these 
Table I : Auto antibodies in 100 patients with habitual abortion.

\begin{tabular}{|l|cc|}
\hline & No. & $(\%)$ \\
\hline Negative patients & 66 & \\
Positive patients & 34 & \\
Antinuclear antibodies & 3 & $(3)$ \\
Anticardiolipin antibodies & 28 & $(82.4)$ \\
IgG & 18 & $(64.3)$ \\
IgM & 6 & $(21.4)$ \\
IgG + IgM & 4 & $(14.3)$ \\
Lupus anticoagulant & 1 & $(1)$ \\
Antithyroid antibodies & 2 & $(2)$ \\
\hline
\end{tabular}

Table II : Association of autoantibodies in women with habitual abortion.

\begin{tabular}{|c|c|c|c|c|c|c|c|}
\hline & Antibody alone & \multicolumn{6}{|c|}{ Antibody Association } \\
\hline $\mathrm{aCL}$ & 22 & $\mathrm{X}$ & $X$ & $\mathrm{X}$ & $X$ & $X$ & \\
\hline LA & 1 & $X$ & $\mathrm{X}$ & & & & $X$ \\
\hline ANA & 3 & & $\mathrm{X}$ & $x$ & & & \\
\hline aTH & 1 & 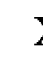 & & & $\mathrm{X}$ & & \\
\hline No. & & 1 & 1 & 1 & 1 & 2 & 1 \\
\hline Total & $27(79.4)$ & & 20.6) & & & & \\
\hline
\end{tabular}

ANA = antinuclear antibodies; $\mathrm{aCL}=$ anticardiolipin antibodies; $\mathrm{LA}=$ lupus anticoagulant; a $\mathrm{Th}=$ antithyroid antibodies

Table III : Treatment with solupred ${ }^{\circledR}$ in the first trimester and or low-dose aspirin until the end of the seventh month, in women with habitual abortion.

\begin{tabular}{|l|c|c|c|}
\hline \multicolumn{1}{|c|}{ Group of patients } & No. of patient & Successful births & Abortions \\
\hline Antibody-negative & & & \\
solupred ${ }^{\circledR}+$ aspirin & 33 & $30(90.9)$ & $3(9.1)$ \\
Aspirin alone & 33 & $25(75.7)$ & $8(24.3)$ \\
Antibody - positive & 34 & $29(85.2)$ & $5(14.8)$ \\
Solupred ${ }^{\circledR}+$ aspirin & & & \\
\hline
\end{tabular}


cases $(82.4 \%)$. This percentage is in accordance with findings previously published. ${ }^{(6,8)} \mathrm{IgG} \mathrm{aCl}$ were twice as frequent as $\operatorname{IgM}$.

Antithyroid antibodies were observed in only $2 \%$ of the patients. LA were found in very few cases and generally associated with aCL. Elevated ANA was observed in $3 \%$ of patients. These Percentage are in accordance with previously published findings.

Solupred ${ }^{\circledR}$ and aspirin treatments were superior to aspirin treatment alone in auto antibodies negative women: the success rate was $80.9 \%$ compared with $75.7 \%$ in patients given aspirin alone $(\mathrm{P}<0.01)$.

Previously, the outcome of pregnancies was followed in a similar cohort of $102 \mathrm{HA}$ patients without treatment ${ }^{(5)}$ and $58 \%$ resulted in births. This observation would mean that low - dose aspirin could foster pregnancy in auto antibodies negative patients. However, in a recent study ${ }^{(9)}$ a difference was found in the success rate in HA women treated with either aspirin $70 \%$ ) or placebo $(70 \%)$.

Solupred $\left.{ }^{(}\right)$and aspirin treatments have the same success rate in both autoantibodies - negative and autoantibodies - positive women. The results presented here confirm those of a recent study ${ }^{(8)}$.

This series of 34 treated patients established that solupre $\left.{ }^{(}\right)$and aspirin treatment is safe, in accordance with previous reports ${ }^{(8)}$. This contrasts with other studies which described Adverse side effects (e.g. hypertension, diabetes mellitus and prematurity) in the solupred ${ }^{\circledR}$ and aspirin - treated group. This contrast may be due to the difference in the duration of solupred treatment which was 2 months in the present study, and 3.5 months in Geva's study ${ }^{(8)}$.

\section{REFERENCES}

1- Mishell, D. R. Recurrent abortion J. Reprod Med., $1993 ; 38,250-259$.

2- Stirrat, G. M. Recurent miscarriage II: Clinical association, causés, and management. Lancet, 1990; 336, 728-733. \{IS\} PMedline\}.

3- Gleicher, N. Auto antibodies in infertility: current opinion. Hum. reprod. Update, 1998; 4, 169-176. \{Free full text).

4. Hill, J. A. Immunologic factors in spontaneous abortion. In (cds) Bronson, R. A. Alexender, N. J. Andreson, D. J. etal. Reproductive immunology. Black well science, Paris France 1996; pp. 433-442.

5- Renzikoff - Etievant, M. F. Results of 15 centcrs france. In chaouat, G. and Mowbray, J, (eds), Cellular and Biology of the Materno - Fetal Relationship. Colloque ISERM/john Libbey, 1991; 212, pp. 303-306.

6- Stephenson, M. D. Frequency of factors associated with habitual abortion in 197 couples. Fertil. Steril., 1996; 66, 24-29. \{ISI\} \{Medline\}.

7. KnaPP RG, Miller Mc. Definin normality using the predictive value method in: clinical epidemiology and Biostatistics. National Medical series., Mass Publishing CP. 1992; pp. 53-60.

8- Gfena, E., Amil, A., Lerner-Geva, L., eta 1. Prevention of pregnancy loss in autoantibody scropositive women. Lancet, 1998; 351, 34-35.

9- Mtulppala, M. Martunen, M., Soderstrom - Anttila, V. et al. Low-dose aspirin in prevention of miscarriage in women with unexplained or autoimmune related recurrent miscarriage: effect on prostacylin and thromboxane A2 production. Hum. Reprod., 1997; 12, 1567-1572. \{Abstract\}.

10-Robert, A. Iwo different incubation times for the activated partial thromboplastim time (APTT) : a new criterion for diagnosis of lupus anticoagulant. Thromb. Hacmost., 1994; 71, 220-224 \{IS\}.

11- Maejima. M., Fujii, T., Okai, T. et al. Beta2glycoprotein- dependent anticardiolipin antibody in carly recurrent spontancous abortion. Hum. Reprod., 1997; 12, 2140-2142 \{Abstract\}.

12- Czarocka B; Ruf $J$ and ferr and M. Purjfication of the human thyroid peroxides and its identification as the micro somal antigen involved in autoimmune thyroid discase. FEBS 1985; 10. 